\title{
DIFFERENCE BETWEEN USING TABULATED AND EXACT VALUES OF THERMAL PROPERTIES OF MATERIALS IN NUMERICAL SIMULATIONS OF HEAT TRANSFER THROUGH A HIGH-PERFORMANCE WINDOW
}

\author{
MIHA JUKIĆ \& SABINA JORDAN \\ Slovenian National Building and Civil Engineering Institute, Slovenia
}

\begin{abstract}
The thermal properties of materials, primarily the thermal conductivity, are an essential input for numerical modelling of heat transfer in buildings and building components. When determining them according to relevant European standards, it is not uncommon to encounter materials for which the exact values are not appropriately specified and the tabulated values in standards are overly conservative. In such situations, the thermal conductivity of the material can be determined by measurement. However, this approach may prove inconvenient and too expensive, especially if the material in question turns out to have little influence on the overall thermal performance of the product. It is, therefore, of great interest to know how the thermal performance is affected by choosing either the accurate (measured) or the conservative (tabulated) value of the thermal conductivity. In this work, the two approaches are compared in a practical example - a high-performance window, Jelovica Jelofuture - using numerical simulations. Our study shows that modifying the thermal properties of individual materials generally leaves the thermal transmittances of the frame $\left(\mathrm{U}_{\mathrm{f}}\right)$ and the window $\left(\mathrm{Uw}_{\mathrm{w}}\right)$ almost unaffected. If all of the materials considered are modified simultaneously, $\mathrm{U}_{\mathrm{f}}$ changes by $1-2 \%$ while the change in $U_{W}$ remains below $1 \%$. However, due to their small values, the calculated changes of $U_{\mathrm{f}}$ and $\mathrm{U}_{\mathrm{W}}$ may be significantly affected (further increased or reduced) by the rounding of the results according to the relevant standards. In contrast, using the tabulated value of linear thermal transmittance $\left(\Psi_{\mathrm{g}}\right)$ of the junction with the glazing leads to an overestimation of $U_{\mathrm{W}}$ by up to $15 \%$.

Keywords: thermal transmittance, numerical simulation, conductivity, tabulated and exact values, practical example.
\end{abstract}

\section{INTRODUCTION}

The EU Construction Products Regulation [1] requires the placement of construction products on the European market to be supported by assessment and declaration of their performance, with energy efficiency as one of the most important aspects. The thermal performance of many products, including doors and windows, is most conveniently assessed by performing numerical simulations of heat transfer. The latter is subject to national and international standards which, along with prescribing the methods, set restrictions on the input data for the analysis.

The present European standards which govern numerical modelling of heat transfer in doors and windows, e.g. [2], [3], allow several ways to determine the material properties used in the modelling. The preferred option is to use the tabulated values from the standards. Alternatively, the material properties may be taken from the declaration of performance of a specific product, or determined by measurement. The declared values are usually provided for the "important" products, e.g. thermal insulation, and the tabulated values usually suffice for the more generic materials, such as glass or steel. Still, it is not uncommon to encounter materials for which the thermal properties are not appropriately specified and the tabulated values are overly conservative. In such cases the properties can be determined by 
measurement: however, this approach may prove inconvenient and too expensive, especially if the material in question only has a minor role in the analysed building or building component. It is therefore of great interest to know how the thermal performance is affected by using either the accurate (measured) or the conservative (tabulated) values of thermal properties. Studies that examined the influence of different parameters on the thermal performance of windows have been performed in the past, e.g. [4]-[6], but they mostly focused on the design aspect, i.e. optimising the window geometry, details and constituent materials.

In the present work, the focus was set on the assessment of the thermal performance of a finalised product in accordance with the relevant European standards [3], [7], [8]. The goal of the study was to investigate using a practical example - a high-performance window, Jelovica Jelofuture - how the choice between using the accurate or the tabulated values of thermal properties in numerical simulations of heat transfer influences the thermal performance of a window.

\section{METHODOLOGY}

The starting point of this study was the thermal performance assessment of a high-performance window, Jelovica Jelofuture. The assessment was based on numerical simulations of heat transfer, and comprised the calculations of the thermal transmittance of the window frame $\left(\mathrm{U}_{\mathrm{f}}\right)$ the linear thermal transmittance at the junction of the frame and the glazing $\left(\Psi_{\mathrm{g}}\right)$, and the thermal transmittance of the window $\left(\mathrm{U}_{\mathrm{W}}\right)$, all in accordance with the relevant European standards [3], [8]. In the original assessment, tabulated values of thermal conductivity had been used for several materials.

In the present study, the conservative, tabulated values of thermal properties used in the original assessment were modified in order to examine their influence on the thermal performance of the window and its elements. The modifications were applied in different combinations, individually and collectively. Numerical simulations of heat transfer were then repeated for each combination.

Two approaches were used for the subsequent calculations. The first one (referred to as "According to standard" in the tables below) strictly followed the procedures defined in standards [3], [8], which also specify the rounding of the results, i.e. thermal transmittances $\mathrm{U}_{\mathrm{f}}, \Psi_{\mathrm{g}}$, and $\mathrm{U}_{\mathrm{W}}$. Since $\mathrm{U}_{\mathrm{f}}$ is an input for the calculation of $\Psi_{\mathrm{g}}$, and both are used to calculate $\mathrm{U}_{\mathrm{W}}$, the rounding may affect the results to a certain extent. In the second approach (referred to as "Without rounding" in the tables below) the calculations were carried out without intermediate rounding, in order to give more accurate and physically sensible results, and provide a better insight into the physical consequences of the applied modifications.

\subsection{Description of the specimen}

The window frame profiles of the high-performance window, Jelovica Jelofuture (the investment for the development of the window Jelovica Jelofuture in the scope of the project Jelofuture was co-financed by the Republic of Slovenia and the European Union - European Regional Development Fund) are designed as a combination of wood, PVC, and aluminium. The sill profile (D1) is depicted in Fig. 1(a). The central part of the frame consists of a PVC profile with highly insulative polyisocyanurate (PIR) foam inserts. The inner part of the frame and the casement are made of wood, and the outer cover is made of aluminium profile with a PIR foam insert. Silicone is used to seal the gap between the glazing unit and the casement. Expansion tape is used between the PVC and the wooden part of the frame. The gaskets are made of EPDM-based material. The head profile (D2) in Fig. 1(b) slightly differs from the 
sill profile - the casement has a different shape and two additional PIR foam inserts are used. The jamb profiles are identical to the head profile.

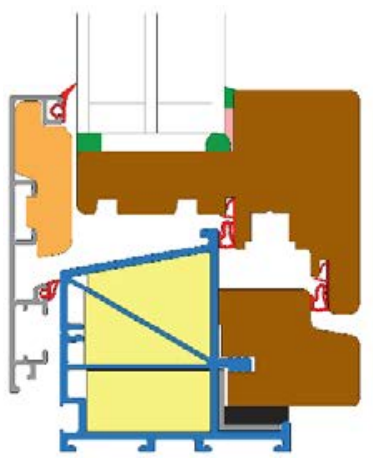

(a)

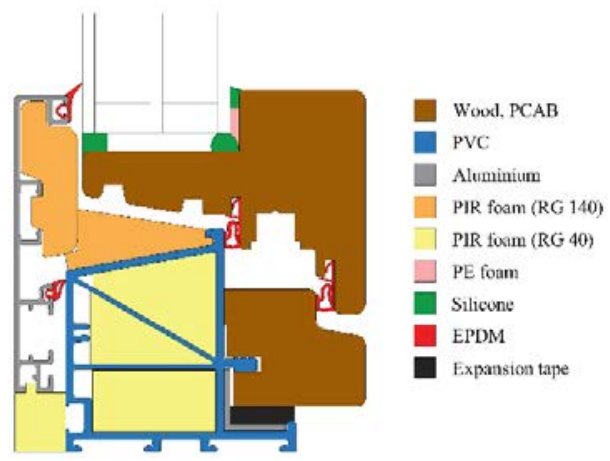

(b)

Figure 1: Window frame profiles. (a) Sill profile - D1; (b) Head and jamb profiles - D2.

Two different insulative glazing units (IGUs) were considered in this study. Both were triple-glazed, filled with argon, and had two low-emissivity coatings. The first one was $48 \mathrm{~mm}$ thick (4:/18/4/18/:4), with thermal transmittance $\mathrm{U}_{\mathrm{g}}=0.5 \mathrm{~W} / \mathrm{m}^{2} \mathrm{~K}$. The second was $44 \mathrm{~mm}$ thick $(8: / 10 / 8 / 10 /: 8)$, with thermal transmittance $\mathrm{U}_{\mathrm{g}}=0.8 \mathrm{~W} / \mathrm{m}^{2} \mathrm{~K}$. In the following text, they are referred to as $\mathrm{IGU}_{05}$ and $\mathrm{IGU}_{08}$, respectively. In both cases a "Swisspacer Ultimate" glazing spacer was used.

Single casement windows of two standard sizes were analysed. Their overall frame dimensions (width $\times$ height) were $1.23 \mathrm{~m} \times 1.48 \mathrm{~m}$ and $1.48 \mathrm{~m} \times 2.18 \mathrm{~m}$. According to [7], these may represent all windows with an overall area under/over $2.3 \mathrm{~m}^{2}$, respectively.

\subsection{Calculation of thermal transmittances $\mathrm{U}_{\mathrm{f}}, \Psi_{\mathrm{g}}$, and $\mathrm{U}_{\mathrm{W}}$}

Thermal transmittance of the window frame $\left(U_{f}\right)$ was determined with numerical simulations of heat transfer according to the standard [3]. The simulations were performed using Physibel Bisco 11.0 software. Thermal properties (conductivity and emissivity) of materials were determined in accordance with the standard [3]. Their values and the details of the procedure are given in Section 2.3. The convective and the radiative heat transfer in cavities were treated using the single equivalent thermal conductivity method described in the standard [3]. The glazing was replaced by a $36 \mathrm{~mm}$ thick insulative panel extending $190 \mathrm{~mm}$ from the edge of the frame. The boundary conditions used in the simulations are listed in Table 1.

Table 1: Boundary conditions used in numerical simulations.

\begin{tabular}{|l|c|c|}
\hline Surface & Air temperature $\left({ }^{\circ} \mathrm{C}\right)$ & Surface resistance $\left(\mathrm{m}^{2} \mathrm{~K} / \mathrm{W}\right)$ \\
\hline External & 0 & 0.04 \\
Internal - normal & 20 & 0.13 \\
Internal - reduced (corners) & 20 & 0.20 \\
\hline
\end{tabular}

Linear thermal transmittance $\left(\Psi_{\mathrm{g}}\right)$ at the junction of the frame and the glazing was determined according to the standard [3] for all combinations of different frame profiles and different glazing units. For each case a numerical model was developed, similar to the one 
used for the calculation of $U_{f}$, but with the insulation panel replaced by the actual glazing. The argon filling was modelled with a replacement material with an equivalent thermal conductivity. The glazing spacers were modelled using the two-box method described in the ift guideline [9]. Linear thermal transmittance $\left(\Psi_{\mathrm{g}}\right)$ was then calculated from the total heat flow through the numerical model, the thermal transmittance of the glazing $\left(U_{g}\right)$ and the previously determined thermal transmittance of the window frame $\left(\mathrm{U}_{\mathrm{f}}\right)$.

Thermal transmittance of the window $\left(\mathrm{U}_{\mathrm{W}}\right)$ was calculated from thermal transmittances $\mathrm{U}_{\mathrm{g}}, \mathrm{U}_{\mathrm{f}}$, and $\Psi_{\mathrm{g}}$ in accordance with the standard [8]. It was determined for two standard window sizes $(123 \mathrm{~cm} \times 148 \mathrm{~cm}$ and $148 \mathrm{~cm} \times 218 \mathrm{~cm})$ and two types of glazing.

\subsection{Thermal properties}

In the original thermal performance assessment, the thermal properties were determined as follows. Tabulated values of thermal conductivity, taken from the relevant standards [3], [10], were used for most materials, with two exceptions. The conductivity of the PIR foam (two types) was taken from the declaration of performance and the conductivity of the expansion tape was measured by an accredited institute. Due to the insufficient number of measurements, the latter was magnified by a factor of 1.25 in accordance with the standard [3]. Emissivities of all materials were taken from the standard [3]. The thermal conductivities and emissivities of materials are collected in Table 2.

Table 2: Thermal conductivities (original and modified values) and emissivities of materials used in numerical simulations.

\begin{tabular}{|l|c|c|c|}
\hline Material & Conductivity $(\mathrm{W} / \mathrm{mK})$ & $\begin{array}{c}\text { Modified } \\
\text { conductivity } \\
(\mathrm{W} / \mathrm{mK})\end{array}$ & Emissivity \\
\hline Aluminium (powder coated) & 160 & - & 0.9 \\
PVC & 0.17 & $0.16^{\text {(A) }}$ & 0.9 \\
Wood, PCAB (spruce) & 0.11 & $0.13^{\text {(B) }}$ & 0.9 \\
Puren PIR NE40-200 RG 140 & 0.036 & - & 0.9 \\
Puren PIR NE40-200 RG 40 & 0.027 & - & 0.9 \\
PE foam & 0.05 & $0.04^{\text {(A) }}$ & 0.9 \\
Silicone & 0.35 & $0.30^{\text {(A) }}$ & 0.9 \\
EPDM & 0.25 & $0.20^{\text {(A) }}$ & 0.9 \\
Expansion tape Chemiefac 3 & $0.0456 \times 1.25=0.057$ & $0.0456^{(\mathrm{A})}$ & 0.9 \\
complete & 0.035 & - $^{-}$ & 0.9 \\
Insulation panel & &
\end{tabular}

The linear thermal transmittance $\left(\Psi_{\mathrm{g}}\right)$ of the glazing spacer was calculated as described in the previous section (as opposed to using a tabulated value) and the thermal transmittance of the IGU was taken from the declaration of performance.

Modifications of the original thermal properties can be divided into two groups. The purpose of group (A) was to determine whether the thermal performance of a window could be substantially improved by utilising more accurate (non-tabulated) thermal conductivities of individual materials. A positive answer would justify the investment of time and resources into obtaining the appropriate documentation (measurement or declaration of performance). 
In this group the thermal conductivities of PVC, PE foam, silicone, and EPDM were reduced by $5-20 \%$. The modified values, denoted by (A) in Table 2, were chosen based on previous experience with such materials. The conductivity of the expansion tape was also reduced by omitting the factor 1.25 , as would be the case if the measured conductivity was an average value of three or more measurements, instead of just one. The modifications in group (A) were applied individually and collectively to observe their impact on the thermal transmittances $\mathrm{U}_{\mathrm{f}}, \Psi_{\mathrm{g}}$, and $\mathrm{U}_{\mathrm{W}}$.

Group (B) comprises two modifications of a different nature. Here, the original thermal properties were replaced with more conservative values. The conductivity of the wood was increased from $0.11 \mathrm{~W} / \mathrm{mK}$ (tabulated value for the specific tree species) to $0.13 \mathrm{~W} / \mathrm{mK}$ (general tabulated value for softwood). The modified value is denoted by (B) in Table 2. Also, the tabulated value, $\Psi_{\mathrm{g}}=0.06 \mathrm{~W} / \mathrm{mK}$, was used for the linear thermal transmittance at the junction of the frame and the glazing. It corresponds to a thermally improved spacer in combination with triple glazing and low emissivity glass, according to the standard [3]. This value is roughly twice the calculated value of $\Psi_{\mathrm{g}}$. The second modification only influences the calculation of $U_{\mathrm{w}}$, while the first one also affects the calculation of $U_{\mathrm{f}}$ and $\Psi_{\mathrm{g}}$.

\section{RESULTS AND DISCUSSION}

\subsection{Thermal transmittance of the window frame, $\mathrm{U}_{\mathrm{f}}$}

Thermal transmittances of the window frame profiles D1 (sill) and D2 (head and jambs), determined for the original and the modified material properties, are collected in Table 3. Each value is accompanied by the relative difference $\left(\Delta_{\text {rel }}\right)$ from the original $U_{f}$, i.e. thermal transmittance of the frame with the original thermal properties. The table shows the unrounded and rounded results.

Table 3: Thermal transmittance $\left(\mathrm{U}_{\mathrm{f}}\right)$ of window frame profiles $\mathrm{D} 1$ and $\mathrm{D} 2$ - calculated according to standard, and without rounding, for different modifications of thermal properties.

\begin{tabular}{|l|cc|cc|cc|cc|}
\hline \multirow{3}{*}{$\begin{array}{l}\text { Modified } \\
\text { material }\end{array}$} & \multicolumn{7}{|c|}{$\mathrm{U}_{\mathrm{f}}\left(\mathrm{W} / \mathrm{m}^{2} \mathrm{~K}\right)$} \\
\cline { 2 - 9 } & $\begin{array}{c}\text { Without } \\
\text { rounding } \\
*\end{array}$ & $\Delta_{\text {rel }} * *$ & $\begin{array}{c}\text { Diccording } \\
\text { to standard* }\end{array}$ & $\Delta_{\text {rel }}$ & $\begin{array}{c}\text { Without } \\
\text { rounding }\end{array}$ & $\Delta_{\text {rel }}$ & $\begin{array}{c}\text { According } \\
\text { to standard }\end{array}$ & $\Delta_{\text {rel }}$ \\
\hline Original & 0.8485 & & 0.85 & & 0.7223 & & 0.72 & \\
PVC & 0.8418 & $-0.8 \%$ & 0.84 & $-1.2 \%$ & 0.7159 & $-0.9 \%$ & 0.72 & $0.0 \%$ \\
Silicone & 0.8464 & $-0.2 \%$ & 0.85 & $0.0 \%$ & 0.7206 & $-0.2 \%$ & 0.72 & $0.0 \%$ \\
EPDM & 0.8464 & $-0.2 \%$ & 0.85 & $0.0 \%$ & 0.7206 & $-0.2 \%$ & 0.72 & $0.0 \%$ \\
PE foam & 0.8468 & $-0.2 \%$ & 0.85 & $0.0 \%$ & 0.7210 & $-0.2 \%$ & 0.72 & $0.0 \%$ \\
Expansion tape & 0.8473 & $-0.1 \%$ & 0.85 & $0.0 \%$ & 0.7214 & $-0.1 \%$ & 0.72 & $0.0 \%$ \\
All in group & 0.8350 & $-1.6 \%$ & 0.84 & $-1.2 \%$ & 0.7113 & $-1.5 \%$ & 0.71 & $-1.4 \%$ \\
(A) & & & & & & & & \\
Wood & 0.8837 & $4.1 \%$ & 0.88 & $3.5 \%$ & 0.7490 & $3.7 \%$ & 0.75 & $4.2 \%$ \\
\hline
\end{tabular}

*See Section 2 for the description of the calculation procedures.

**Relative difference from the original value. 
Modifying the thermal conductivity of an individual material from group (A) hardly affects the transmittance of the frame. In most cases $U_{f}$ changes by a mere $0.2 \%$, even with the reduction of the conductivity by $15-20 \%$. A slightly bigger improvement of $U_{f}$ is observed with PVC, despite the smaller reduction of its thermal conductivity (approx. 6\%). This is because PVC constitutes part of the frame core which provides most of the thermal protection. Being surrounded by a superior material (PIR foam), PVC acts as a minor thermal bridge. Nevertheless, the improvement of $U_{f}$ is still below 1\%. Applying all modifications from group (A) simultaneously, improves the thermal transmittance of the frame by $1.5 \%$.

Thermal conductivity of wood has a more noticeable influence on $U_{\mathrm{f}}$. Increasing the thermal conductivity by $18 \%$, which is comparable to the modifications in group (A), results in an approximately $4 \%$ larger $\mathrm{U}_{\mathrm{f}}$. Compared to group (A), this increase is an order of magnitude greater. This is not surprising, since wood covers virtually the whole inner surface of the frame in considerable thickness and thus creates a uniform thermally protective layer. On the contrary, the materials in group (A) mostly represent smaller elements scattered over the frame profile. The other modification in group (B) - application of a tabulated value for $\Psi_{\mathrm{g}}$ - does not affect the $\mathrm{U}_{\mathrm{f}}$ calculation procedure.

The observations described above refer to the unrounded values of $U_{f}$. Subsequent rounding of those values has a significant impact on the differences between them. According to the standard [3], $\mathrm{U}_{\mathrm{f}}$ has to be rounded to two significant figures, which implies a change in the order of $1 \%$. Improvements of $U_{f}$, observed on the unrounded values, are generally much smaller and therefore irrelevant. This is confirmed by comparing the rounded results in Table 3. Individual modifications of thermal properties from group (A) have virtually no influence on the rounded value of $U_{f}$. Only when they are all combined is the improvement of $U_{f}$ sufficiently big not to be annulled by rounding. The only relevant modification by this criterion is the increase of the thermal conductivity of wood.

Graphical results of the numerical simulation for the head/jamb profile (D2) with the original thermal properties are presented in Fig. 2 which displays the temperature field (a) and the heat flux field (b) in the frame profile.

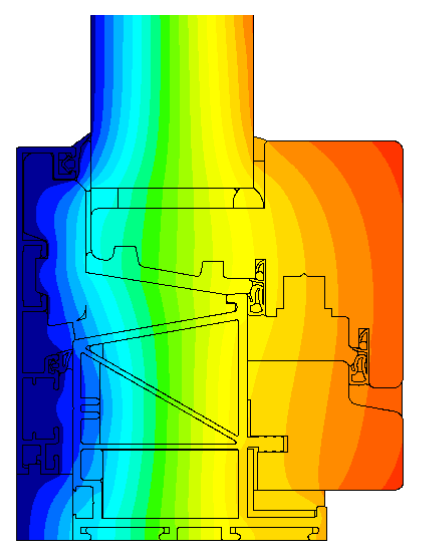

(a)
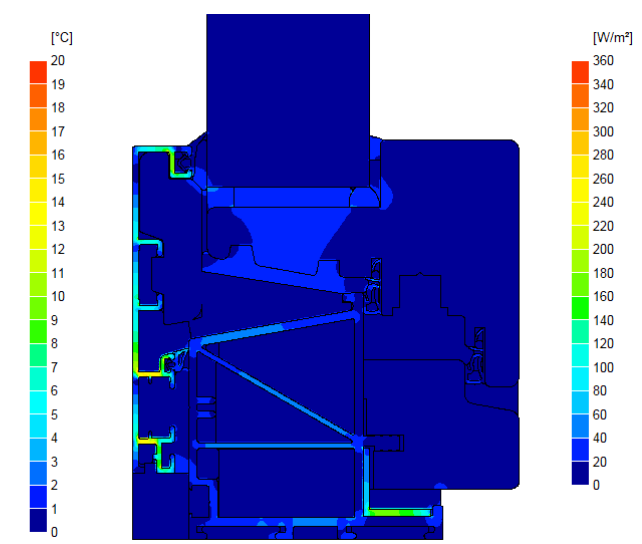

(b)

Figure 2: Graphical output of the numerical simulation for the head/jamb profile (D2) with the original thermal properties. (a) Temperature field; (b) Heat flux field. 
3.2 Linear thermal transmittance $\left(\Psi_{\mathrm{g}}\right)$ at the junction of the frame and the glazing

The linear thermal transmittances $\left(\Psi_{\mathrm{g}}\right)$ at the junction of the window frame and the glazing were determined for all combinations of the frame profiles (D1 and D2) and the glazing units ( $\mathrm{IGU}_{05}$ and $\mathrm{IGU}_{08}$ ), applying the different modifications of thermal parameters described in Section 2.3. The results are collected in Table 4 for $\mathrm{IGU}_{05}\left(\mathrm{U}_{\mathrm{g}}=0.5 \mathrm{~W} / \mathrm{m}^{2} \mathrm{~K}\right)$, and in Table 5 for $\mathrm{IGU}_{08}\left(\mathrm{U}_{\mathrm{g}}=0.8 \mathrm{~W} / \mathrm{m}^{2} \mathrm{~K}\right)$. Each $\Psi_{\mathrm{g}}$ is accompanied by its relative difference, $\Delta_{\text {rel }}$, from the original value. Against intuitive expectation, $\Psi_{\mathrm{g}}$ takes smaller values for the glazing with lower $U_{\mathrm{g}}$. The reason lies in the greater thickness of the glass panes $\left(8 \mathrm{~mm}\right.$ in $\mathrm{IGU}_{08} \mathrm{vs} .4 \mathrm{~mm}$ in $\left.\mathrm{IGU}_{05}\right)$.

Table 4: Linear thermal transmittance $\left(\Psi_{\mathrm{g}}\right)$ at the junction of the window frame profile (D1 or D2) and the glazing $\mathrm{IGU}_{05}\left(\mathrm{U}_{\mathrm{g}}=0.5 \mathrm{~W} / \mathrm{m}^{2} \mathrm{~K}\right)$, calculated according to standard and without rounding, for different modifications of thermal properties.

\begin{tabular}{|l|cc|cc|cc|cc|}
\hline \multirow{3}{*}{$\begin{array}{l}\text { Modified } \\
\text { material }\end{array}$} & \multicolumn{7}{|c|}{$\Psi_{\mathrm{g}}(\mathrm{W} / \mathrm{mK})$} \\
\cline { 2 - 9 } & $\begin{array}{c}\text { Without } \\
\text { rounding* }\end{array}$ & $\Delta_{\text {rel }} * *$ & $\begin{array}{c}\text { According } \\
\text { to standard* }\end{array}$ & $\Delta_{\text {rel }}$ & $\begin{array}{c}\text { Without } \\
\text { rounding }\end{array}$ & $\Delta_{\text {rel }}$ & $\begin{array}{c}\text { According } \\
\text { to standard }\end{array}$ & $\Delta_{\text {rel }}$ \\
\hline Original & 0.02242 & & 0.022 & & 0.02292 & & 0.023 & \\
PVC & 0.02242 & $0.0 \%$ & 0.023 & $4.5 \%$ & 0.02297 & $0.2 \%$ & 0.022 & $-4.3 \%$ \\
Silicone & 0.02237 & $-0.2 \%$ & 0.022 & $0.0 \%$ & 0.02287 & $-0.2 \%$ & 0.023 & $0.0 \%$ \\
EPDM & 0.02232 & $-0.4 \%$ & 0.022 & $0.0 \%$ & 0.02292 & $0.0 \%$ & 0.023 & $0.0 \%$ \\
PE foam & 0.02252 & $0.4 \%$ & 0.022 & $0.0 \%$ & 0.02302 & $0.4 \%$ & 0.023 & $0.0 \%$ \\
Expansion tape & 0.02242 & $0.0 \%$ & 0.022 & $0.0 \%$ & 0.02292 & $0.0 \%$ & 0.023 & $0.0 \%$ \\
All in group A & 0.02242 & $0.0 \%$ & 0.022 & $0.0 \%$ & 0.02287 & $-0.2 \%$ & 0.023 & $0.0 \%$ \\
Wood & 0.02287 & $2.0 \%$ & 0.023 & $4.5 \%$ & 0.02317 & $1.1 \%$ & 0.023 & $0.0 \%$ \\
\hline
\end{tabular}

*See Section 2 for the description of the calculation procedures.

**Relative difference from the original value.

A distinction is made between the values of $\Psi_{\mathrm{g}}$ calculated in accordance with the standard [3], and the values calculated without rounding. The former were calculated using the rounded values of $U_{f}$. The latter were calculated using the unrounded values of $U_{f}$ to provide more accurate and physically sensible results.

The unrounded results for $\mathrm{IGU}_{05}$ in Table 4 reveal that the modifications of material properties have no significant influence on the linear thermal transmittance of the glazing spacer. The relative differences $\left(\Delta_{\text {rel }}\right)$ do not exceed $0.4 \%$ except in the case of wood. The increased thermal conductivity of wood produces a $1-2 \%$ larger $\Psi_{\mathrm{g}}$. In Table 5 , the relative differences $\left(\Delta_{\text {rel }}\right)$ for $\mathrm{IGU}_{08}$ are even smaller.

Some modifications from group (A) increase the value of $\Psi_{\mathrm{g}}$, while others decrease it. If they are all applied simultaneously, their effects balance out.

Rounding of $\Psi_{\mathrm{g}}$ to two significant figures plays an even more important role than it did in the case of $U_{\mathrm{f}}$. It can change the typical $\Psi_{\mathrm{g}}$ value of an advanced thermally improved spacer (around $0.03 \mathrm{~W} / \mathrm{mK}$ ) by approximately $3 \%$. This is confirmed by inspecting the results in Tables 4 and 5, calculated according to standard. Most of the small changes of $U_{f}$, caused by the modified thermal properties are voided. Some, on the other hand, are notably increased. 
Table 5: Linear thermal transmittance $\left(\Psi_{\mathrm{g}}\right)$ at the junction of the window frame profile (D1 or D2) and the glazing $\mathrm{IGU}_{08}\left(\mathrm{U}_{\mathrm{g}}=0.8 \mathrm{~W} / \mathrm{m}^{2} \mathrm{~K}\right)$, calculated according to standard and without rounding, for different modifications of thermal properties.

\begin{tabular}{|l|cc|cc|cc|cc|}
\hline \multirow{3}{*}{$\begin{array}{l}\text { Modified } \\
\text { material }\end{array}$} & \multicolumn{7}{|c|}{$\Psi_{\mathrm{g}}(\mathrm{W} / \mathrm{mK})$} \\
\cline { 2 - 9 } & $\begin{array}{c}\text { Without } \\
\text { rounding* }\end{array}$ & $\Delta_{\text {rel }} * *$ & $\begin{array}{c}\text { According } \\
\text { to standard* }\end{array}$ & $\Delta_{\text {rel }}$ & $\begin{array}{c}\text { Without } \\
\text { rounding }\end{array}$ & $\Delta_{\text {rel }}$ & $\begin{array}{c}\text { According } \\
\text { to standard }\end{array}$ & $\Delta_{\text {rel }}$ \\
\hline Original & 0.03547 & & 0.035 & & 0.03547 & & 0.036 & \\
PVC & 0.03547 & $0.0 \%$ & 0.036 & $2.9 \%$ & 0.03547 & $0.0 \%$ & 0.035 & $-2.8 \%$ \\
Silicone & 0.03552 & $0.1 \%$ & 0.035 & $0.0 \%$ & 0.03547 & $0.0 \%$ & 0.036 & $0.0 \%$ \\
EPDM & 0.03537 & $-0.3 \%$ & 0.035 & $0.0 \%$ & 0.03537 & $-0.3 \%$ & 0.035 & $-2.8 \%$ \\
PE foam & 0.03557 & $0.3 \%$ & 0.035 & $0.0 \%$ & 0.03552 & $0.1 \%$ & 0.036 & $0.0 \%$ \\
Expansion tape & 0.03552 & $0.1 \%$ & 0.035 & $0.0 \%$ & 0.03542 & $-0.1 \%$ & 0.036 & $0.0 \%$ \\
All in group A & 0.03547 & $0.0 \%$ & 0.035 & $0.0 \%$ & 0.03542 & $-0.1 \%$ & 0.036 & $0.0 \%$ \\
Wood & 0.03567 & $0.6 \%$ & 0.036 & $2.9 \%$ & 0.03592 & $1.3 \%$ & 0.036 & $0.0 \%$ \\
\hline
\end{tabular}

*See Section 2 for the description of the calculation procedures.

**Relative difference from the original value.

The slightly "random" values of $\Delta_{\text {rel }}$ (e.g. in the case of PVC: positive for the D1 profile and negative for the D2 profile, while virtually non-existent in the calculation without rounding) are a consequence of calculating $\Psi_{\mathrm{g}}$ with the rounded values of $U_{\mathrm{f}}$.

\subsection{Thermal transmittance of the window, $\mathrm{U}_{\mathrm{W}}$}

Thermal transmittance of the window $\left(\mathrm{U}_{\mathrm{w}}\right)$ was calculated for two standard sizes of single casement windows and two types of glazing ( $\mathrm{IGU}_{05}$ and $\mathrm{IGU}_{08}$ ), applying the different modifications of thermal parameters described in Section 2.3. The results are presented in Table 6 for $\mathrm{IGU}_{05}$ and in Table 7 for IGU $\mathrm{IG}_{08}$. The relative difference $\left(\Delta_{\text {rel }}\right)$ from the original $\mathrm{U}_{\mathrm{W}}$, i.e. determined with the original material properties, is given as well.

Again, calculation according to the standard [8] and calculation without rounding are distinguished in Tables 6 and 7. In the first case, the values of $U_{w}$ were calculated using the rounded values of $U_{\mathrm{f}}$ and $\Psi_{\mathrm{g}}$, which were determined in accordance with the standard [3]. The unrounded values of $U_{w}$ were calculated using the unrounded $U_{f}$ and $\Psi_{g}$ to give more precise results.

The considered modifications of thermal properties only apply to materials in the window frame, while the thermal transmittance of the glazing $\left(\mathrm{U}_{\mathrm{g}}\right)$ remains unchanged. The glazing represents approximately two thirds of the smaller window examined herein $(123 \mathrm{~cm} \times$ $148 \mathrm{~cm})$, and three quarters of the bigger one $(148 \mathrm{~cm} \times 218 \mathrm{~cm})$. It is therefore logical that the thermal transmittance of the window is less sensitive to the modifications than $\mathrm{U}_{\mathrm{f}}$ and $\Psi_{\mathrm{g}}$.

Individual modifications from group (A) have no significant influence on $\mathrm{U}_{\mathrm{W}}$. Even combining all of them only reduces $U_{W}$ by circa $0.5 \%$. The only noteworthy change of $U_{W}$ $(1-1.5 \%)$ is caused by increasing the thermal conductivity of wood. These effects are most notable on the smaller window $(123 \mathrm{~cm} \times 148 \mathrm{~cm})$ with IGU $_{05}$. A larger window size means that a greater portion of the window is insensitive to modifications (glazing). And a larger value of $U_{\mathrm{W}}$, caused by a larger $\mathrm{U}_{\mathrm{g}}$, means that the same absolute changes have a smaller relative value. 
Table 6: Thermal transmittance $\left(\mathrm{U}_{\mathrm{W}}\right)$ of two single casement windows $(123 \mathrm{~cm} \times 148 \mathrm{~cm}$ and $148 \mathrm{~cm} \times 218 \mathrm{~cm})$ using the glazing $\operatorname{IGU}_{05}\left(\mathrm{U}_{\mathrm{g}}=0.5 \mathrm{~W} / \mathrm{m}^{2} \mathrm{~K}\right)-$ calculated according to standard, and without rounding, for different modifications of thermal properties.

\begin{tabular}{|l|cc|cc|cc|cc|}
\hline \multirow{3}{*}{$\begin{array}{l}\text { Modified } \\
\text { material }\end{array}$} & \multicolumn{7}{|c|}{$\mathrm{U}_{\mathrm{W}}\left(\mathrm{W} / \mathrm{m}^{2} \mathrm{~K}\right)$} \\
\cline { 2 - 9 } & $\begin{array}{l}\text { Without } \\
\text { rounding* }\end{array}$ & $\Delta_{\text {rel }} * *$ & $\begin{array}{c}\text { According } \\
\text { to standard* }\end{array}$ & $\Delta_{\text {rel }}$ & $\begin{array}{c}\text { Without } \\
\text { rounding }\end{array}$ & $\Delta_{\text {rel }}$ & $\begin{array}{c}\text { According } \\
\text { to standard }\end{array}$ & $\Delta_{\text {rel }}$ \\
\hline Original & 0.6367 & & 0.64 & & 0.6073 & & 0.61 & \\
PVC & 0.6349 & $-0.3 \%$ & 0.63 & $-1.6 \%$ & 0.6058 & $-0.2 \%$ & 0.61 & $0.0 \%$ \\
Silicone & 0.6361 & $-0.1 \%$ & 0.64 & $0.0 \%$ & 0.6067 & $-0.1 \%$ & 0.61 & $0.0 \%$ \\
EPDM & 0.6362 & $-0.1 \%$ & 0.64 & $0.0 \%$ & 0.6068 & $-0.1 \%$ & 0.61 & $0.0 \%$ \\
PE foam & 0.6366 & $0.0 \%$ & 0.64 & $0.0 \%$ & 0.6071 & $0.0 \%$ & 0.61 & $0.0 \%$ \\
Expansion tape & 0.6365 & $0.0 \%$ & 0.64 & $0.0 \%$ & 0.6070 & $0.0 \%$ & 0.61 & $0.0 \%$ \\
All in group (A) & 0.6330 & $-0.6 \%$ & 0.63 & $-1.6 \%$ & 0.6043 & $-0.5 \%$ & 0.60 & $-1.6 \%$ \\
Wood & 0.6467 & $1.6 \%$ & 0.65 & $1.6 \%$ & 0.6150 & $1.3 \%$ & 0.61 & $0.0 \%$ \\
\hline
\end{tabular}

*See Section 2 for the description of the calculation procedures.

**Relative difference from the original value.

Table 7: Thermal transmittance $\left(\mathrm{U}_{\mathrm{W}}\right)$ of two single casement windows $(123 \mathrm{~cm} \times 148 \mathrm{~cm}$ and $148 \mathrm{~cm} \times 218 \mathrm{~cm})$ using the glazing $\operatorname{IGU}_{08}\left(\mathrm{U}_{\mathrm{g}}=0.8 \mathrm{~W} / \mathrm{m}^{2} \mathrm{~K}\right)$, calculated according to standard and without rounding, for different modifications of thermal properties.

\begin{tabular}{|l|cc|cc|cc|cc|}
\hline \multirow{3}{*}{$\begin{array}{l}\text { Modified } \\
\text { material }\end{array}$} & \multicolumn{7}{|c|}{$\mathrm{UW}_{\mathrm{W}}\left(\mathrm{W} / \mathrm{m}^{2} \mathrm{~K}\right)$} \\
\cline { 2 - 9 } & $\begin{array}{c}\text { Without } \\
\text { rounding* }\end{array}$ & $\Delta_{\text {rel }} * *$ & $\begin{array}{c}\text { According } \\
\text { to standard* }\end{array}$ & $\Delta_{\text {rel }}$ & $\begin{array}{c}\text { Without } \\
\text { rounding }\end{array}$ & $\Delta_{\text {rel }}$ & $\begin{array}{c}\text { According } \\
\text { to standard }\end{array}$ & $\Delta_{\text {rel }}$ \\
\hline Original & 0.8718 & & 0.87 & & 0.8572 & & 0.86 & \\
PVC & 0.8698 & $-0.2 \%$ & 0.87 & $0.0 \%$ & 0.8556 & $-0.2 \%$ & 0.86 & $0.0 \%$ \\
Silicone & 0.8713 & $-0.1 \%$ & 0.87 & $0.0 \%$ & 0.8568 & $0.0 \%$ & 0.86 & $0.0 \%$ \\
EPDM & 0.8710 & $-0.1 \%$ & 0.87 & $0.0 \%$ & 0.8566 & $-0.1 \%$ & 0.86 & $0.0 \%$ \\
PE foam & 0.8715 & $0.0 \%$ & 0.87 & $0.0 \%$ & 0.8570 & $0.0 \%$ & 0.86 & $0.0 \%$ \\
Expansion tape & 0.8714 & $0.0 \%$ & 0.87 & $0.0 \%$ & 0.8569 & $0.0 \%$ & 0.86 & $0.0 \%$ \\
All in group (A) & 0.8680 & $-0.4 \%$ & 0.87 & $0.0 \%$ & 0.8542 & $-0.3 \%$ & 0.85 & $-1.2 \%$ \\
Wood & 0.8819 & $1.2 \%$ & 0.88 & $1.1 \%$ & 0.8651 & $0.9 \%$ & 0.87 & $1.2 \%$ \\
\hline
\end{tabular}

*See Section 2 for the description of the calculation procedures.

**Relative difference from the original value.

The values of $U_{\mathrm{W}}$, calculated according to the standard [8], are mostly unaffected by the modifications from group (A), unless all of them are combined. Even then, a non-zero $\Delta_{\text {rel }}$ is largely a consequence of the original $U_{\mathrm{W}}$ being near the border of being rounded up or down. Modifying the thermal conductivity of wood increases $U_{W}$ by a little more than $1 \%$.

Thermal transmittances of the window $\left(\mathrm{U}_{\mathrm{W}}\right)$, calculated using the tabulated value of $\Psi_{\mathrm{g}}$, are collected in Table 8. They were determined in accordance with the standard [8]. The table shows the results for two standard window sizes and two types of glazing. Here, $\Delta_{\text {rel }}$ represents the relative difference from $U_{W}$, calculated using the original thermal properties 
and the calculated value of $\Psi_{\mathrm{g}}$ (the results with the column tag "According to standard" and row tag "Original" in Tables 6 and 7).

Table 8: Thermal transmittance of the window $\left(\mathrm{U}_{\mathrm{W}}\right)$ calculated using the tabulated value of $\Psi_{\mathrm{g}}=0.06 \mathrm{~W} / \mathrm{mK}$ - results for two window sizes $(123 \mathrm{~cm} \times 148 \mathrm{~cm}$ and $148 \mathrm{~cm} \times 218 \mathrm{~cm})$ and two IGUs $\left(\mathrm{Ug}_{\mathrm{g}}=0.5 \mathrm{~W} / \mathrm{m}^{2} \mathrm{~K}\right.$ and $\left.0.8 \mathrm{~W} / \mathrm{m}^{2} \mathrm{~K}\right)$.

\begin{tabular}{|c|c|c|c|c|c|}
\hline \multirow{3}{*}{ IGU } & \multirow{3}{*}{$\begin{array}{c}\text { Modified } \\
\text { material }\end{array}$} & \multicolumn{4}{|c|}{$\mathrm{U}_{\mathrm{W}}\left(\mathrm{W} / \mathrm{m}^{2} \mathrm{~K}\right)$} \\
\hline & & \multicolumn{2}{|c|}{$123 \mathrm{~cm} \times 148 \mathrm{~cm}$} & \multicolumn{2}{|c|}{$148 \mathrm{~cm} \times 218 \mathrm{~cm}$} \\
\hline & & $\begin{array}{l}\text { According } \\
\text { to standard }\end{array}$ & $\Delta_{\mathrm{rel}} *$ & $\begin{array}{l}\text { According } \\
\text { to standard }\end{array}$ & $\Delta_{\text {rel }}$ \\
\hline \multirow{2}{*}{$\mathrm{U}_{\mathrm{g}}=0.5 \mathrm{~W} / \mathrm{m}^{2} \mathrm{~K}$} & Original & 0.73 & $14.1 \%$ & 0.68 & $11.5 \%$ \\
\hline & Wood & 0.74 & $15.6 \%$ & 0.69 & $13.1 \%$ \\
\hline \multirow{2}{*}{$\mathrm{U}_{\mathrm{g}}=0.8 \mathrm{~W} / \mathrm{m}^{2} \mathrm{~K}$} & Original & 0.93 & $6.9 \%$ & 0.91 & $5.8 \%$ \\
\hline & Wood & 0.94 & $8.0 \%$ & 0.91 & $5.8 \%$ \\
\hline
\end{tabular}

*Relative difference from $U_{\mathrm{w}}$ calculated using the original thermal properties and the calculated $\Psi_{\mathrm{g}}$.

Using the tabulated $\Psi_{\mathrm{g}}=0.06 \mathrm{~W} / \mathrm{mK}$ proves most costly for the smaller window with the $\mathrm{IGU}_{05}$ glazing unit, for which the actual value of $\Psi_{\mathrm{g}}$ is almost three times smaller $(0.022 \mathrm{~W} / \mathrm{mK}$ for the $\mathrm{D} 1$ profile and $0.023 \mathrm{~W} / \mathrm{mK}$ for $\mathrm{D} 2)$. As a consequence, $\mathrm{U}_{\mathrm{W}}$ grows by $14 \%$. A lesser increase of $U_{W}\left(\right.$ by $7 \%$ ) is observed in the case of $I_{08}$, because the actual $\Psi_{\mathrm{g}}$ is slightly larger here $(0.035 \mathrm{~W} / \mathrm{mK}$ for the D1 profile and $0.036 \mathrm{~W} / \mathrm{mK}$ for D2). The values of $\Delta_{\text {rel }}$ are a little lower for the larger window, regardless of the type of glazing.

If thermal conductivity of wood is increased as well, the thermal transmittance of the window grows by additional $1-1.5 \%$. Small deviations of this increase from the results in Tables 6 and 7 are caused by rounding.

\section{CONCLUSIONS}

The goal of this study was to examine how using the conservative, tabulated values of thermal properties in the numerical simulations of heat transfer, instead of obtaining the appropriate documentation which would allow the use of exact ones, affects the calculated values of the thermal transmittance of the window frame $\left(\mathrm{U}_{\mathrm{f}}\right)$, the linear thermal transmittance at the joint of the frame and the glazing $\left(\Psi_{\mathrm{g}}\right)$ and the thermal transmittance of the window $\left(\mathrm{U}_{\mathrm{W}}\right)$.

The study was based on the thermal performance assessment of a high-performance window, Jelovica Jelofuture, whose frame is designed as a combination of wood, PVC, and aluminium with PIR foam inserts, and which uses highly insulative glazing units. The tabulated values of thermal properties, used in the original assessment, were modified individually and collectively before repeating the numerical simulations and comparing the results to the original ones. The modifications comprised reducing the thermal conductivity of PVC and minor elements of the window frame (silicone, EPDM, PE foam, expansion tape); using the general thermal conductivity for softwood, instead of the value for the specific tree species; and using the tabulated value of $\Psi_{\mathrm{g}}$ in the calculation of $U_{\mathrm{W}}$, instead of the exact one. $U_{\mathrm{W}}$ was calculated for two standard sizes $(123 \mathrm{~cm} \times 148 \mathrm{~cm}$ and $148 \mathrm{~cm} \times$ $218 \mathrm{~cm}$ ) of a single casement window.

The study showed that reducing the thermal conductivity of the minor frame elements by $15-20 \%$ had virtually no effect on the thermal transmittances $U_{\mathrm{f}}, \Psi_{\mathrm{g}}$, and $\mathrm{U}_{\mathrm{W}}$. Reducing the thermal conductivity of the PVC profile by $6 \%$ lowered $U_{\mathrm{f}}$ by $1 \%$, but did not really influence $\Psi_{\mathrm{g}}$ and $\mathrm{U}_{\mathrm{W}}$. Combining these modifications had no surprising outcome - an improvement of 
$\mathrm{U}_{\mathrm{f}}$ by a bit more than $1 \%$, and hardly any improvement of $\Psi_{\mathrm{g}}$ and $\mathrm{U}_{\mathrm{W}}$. Thermal conductivity of wood, which forms the inner part of the frame and the casement, proved to have a more noticeable influence. If the tree species had not been specified and the general tabulated value for softwood ( $18 \%$ higher value) had to be used, $\mathrm{U}_{\mathrm{f}}$ would grow by approximately $4 \%$, and $\Psi_{\mathrm{g}}$ and $U_{\mathrm{W}}$ by roughly 1-2\%. Using the tabulated value of $\Psi_{\mathrm{g}}$, instead of calculating the actual one, had by far the greatest consequences, increasing $U_{W}$ by $6-14 \%$. The increase depended partly on the window size, but mostly on the type of the insulating glazing unit which determined the actual value of $\Psi_{\mathrm{g}}$. In our case, the latter was 2-3 times smaller than the tabulated $\Psi_{\mathrm{g}}$.

The observations noted above exclude the effects of rounding the thermal transmittances $\mathrm{U}_{\mathrm{f}}, \Psi_{\mathrm{g}}$, and $\mathrm{U}_{\mathrm{W}}$ according to the relevant standards. Rounding them to two significant figures can usually change their values by an order of $1-2 \%$, or a bit more for $\Psi_{\mathrm{g}}$. This further confirms that most of the considered modifications are irrelevant, as shown by this study. Nevertheless, if the examined thermal transmittance is on the border of being rounded up or down, they may tip the scale.

The results of the study indicate that, in the numerical simulations of heat transfer, tabulated values of thermal conductivity can be used for the minor components of the window frame, such as gaskets, sealants, etc., without significant risk of compromising the (calculated) thermal performance of the analysed product. Attention should be given to materials that occupy larger, continuous areas in the frame cross section (wood in our case) and elements that can represent a thermal bridge. Even small adjustments (such as defining the tree species) may affect the thermal performance considerably.

Using a tabulated value of the linear thermal transmittance $\left(\Psi_{\mathrm{g}}\right)$ at the junction of the frame and the glazing should be avoided, especially if high-end glazing spacers are used. With the advance in technology, many high-performance spacers have been developed which allow values of $\Psi_{\mathrm{g}}$ several times lower than the conservative, tabulated values.

\section{ACKNOWLEDGEMENT}

The authors would like to thank the company Jelovica d.o.o. for their contribution to the research.

\section{REFERENCES}

[1] The European Parliament and the Council of the European Union, Laying down harmonised conditions for the marketing of construction products and repealing Council Directive 89/106/EEC. Regulation (EU) No. 305/2011 of the European Parliament and of the Council (Construction Products Regulation), 2011.

[2] International Organization for Standardization, Thermal bridges in building construction - Heat flows and surface temperatures - Detailed calculations. International standard SIST EN ISO 10211:2017, 2017.

[3] International Organization for Standardization, Thermal performance of windows, doors and shutters - Calculation of thermal transmittance - Part 2: Numerical method for frames. International standard SIST EN ISO 10077-2:2017, 2017.

[4] Gustavsen, A., Grynning, S., Arasteh, D., Jelle, B.P. \& Goudey, H., Key elements of and material performance targets for highly insulating window frames. Energy and Buildings, 43(10), pp. 2583-2594, 2011.

[5] Van Den Bossche, N., Buffel, L. \& Janssens, A., Thermal optimization of window frames. Energy Procedia, 78, pp. 2500-2505, 2015. 
[6] Kalinović, S.M., Djoković, J.M. \& Nikolić, R.R., Influence of windows geometrical parameters on calculations of the heat conduction coefficient. Procedia Engineering, 192, pp. 404-409, 2017.

[7] International Organization for Standardization, Windows and doors - Product standard, performance characteristics - Part 1: Windows and external pedestrian doorsets. International standard SIST EN 14351-1:2006+A2:2016, 2016.

[8] International Organization for Standardization, Thermal performance of windows, doors and shutters - Calculation of thermal transmittance - Part 1: General. International standard SIST EN ISO 10077-1:2017, 2017.

[9] ift-Guideline WA-08engl/3, Thermally improved spacers - Part 1: Determination of representative $\Psi$-values for profile sections of windows. Report, 2015.

[10] International Organization for Standardization, Building materials and products Hygrothermal properties - Tabulated design values and procedures for determining declared and design thermal values. International standard SIST EN ISO 10456:2008, 2008 . 